Tait, R. J. \& Hulse, G. K. (2006) Hospital morbidity and alcohol consumption in less severe psychiatric disorder: 7-year outcomes. British Journal of Psychiatry, 188, 554-559.

H. O'Connell Department of Old Age Psychiatry, Limerick Mental Health Services, St Camillus' Hospital, Limerick, Ireland. Email: hpoconnell@yahoo.ie

doi: 10.I192/bjp.189.6.566a

Authors' reply: Since our study had an observational design, with participants not randomised into groups, we adopted a cautious approach to interpreting findings, and there is the possibility that confounding factors might account for the effect. Questions have now been raised concerning the previously well-accepted belief that moderate alcohol consumption confers protection against ischaemic heart disease, with the possibility that either uncontrolled confounding or unmeasured effect modification in observational studies may account for the purported protective association (Jackson et al, 2005). Therefore, we welcome the suggestion of Dr O'Connell that personality differences may partially account for the difference in outcomes for non-drinkers and moderate drinkers, which increases the plausibility of our findings. Nevertheless, we reiterate the need for a conservative approach when interpreting non-experimental data.

Jackson, R., Broad, J., Conner, J., et al (2005) Alcohol and ischaemic heart disease: probably no free lunch, Lancet, 366, $1911-1912$.

R. J. Tait Queen Elizabeth II Medical Centre, D Block, Nedlands 6009, Western Australia. Email: rjtait@cyllene.uwa.edu.au

G. K. Hulse Queen Elizabeth II Medical Centre, Nedlands, Western Australia doi: 10.1192/bjp.189.6.567

\section{Chronomics of suicides and the solar wind}

Salib \& Cortina-Borja (2006) report an association between month of birth and suicides and this complements findings concerning the season of death in Minnesota. Along the scale of a calendar year, suicides peaked in April to June, which was later than mortality from heart disease and earlier than mortality from accidents. Our results from another continent, with a mid-continental climate, encourage generalisation to people born outside England and Wales. Both studies stacked data, at the outset of analyses, along the scale of the calendar year (Halberg, 1973) or as monthly counts (Salib \& Cortina-Borja, 2006), a limitation subsequently remedied by focus upon broader chronomes (Halberg et al, 2005).

In unstacked data, chronomics resolves (along with trends and deterministic or other chaos) a spectrum of rhythms with many frequencies, in various fields (Halberg et al, 2001), including cis- and transyears, shorter or longer than a year (Halberg et al, 2005).

Richardson et al (1994) reported a periodicity of about 1.3 years for the speed of the solar wind measured by satellites. We found the same and other components of non-photic origin in physiological variables such as blood pressure and heart rate, each studied around the clock for up to decades (Halberg et al, 2001). Such components, also confirmed in the sigma of the speed and the proton content of the solar wind are variable, both in biomedicine and in physics, but they deserve the attention of those concerned with behaviour and can be revealed to the naked eye if the stacking is done after rather than before chronomics. The task remains to compare, before stacking, the chronomes of suicides at birth $v$. death on the same population and thereby to examine any contributions of space weather, among others, to a fatal as well as fetal hypothesis (Salib \& Cortina-Borja, 2006), as attempted in Fig. 1, albeit with data from different populations.

Halberg, F. (1973) Laboratory techniques and rhythmometry. In Biological Aspects of Circadian Rhythms (ed. J. N. Mills). pp. I-26. London: Plenum Press.

Halberg, F., Cornélissen, G., Otsuka, K., et al (200I) Chronomics. Biomedicine and Pharmacotherapy, 55 (suppl. I), I53-190.

Halberg, F., Cornélissen, G., Panksepp, J., et al (2005) Chronomics of autism and suicide. Biomedicine and Pharmacotherapy, 59 (suppl. I), SI00-SI08.

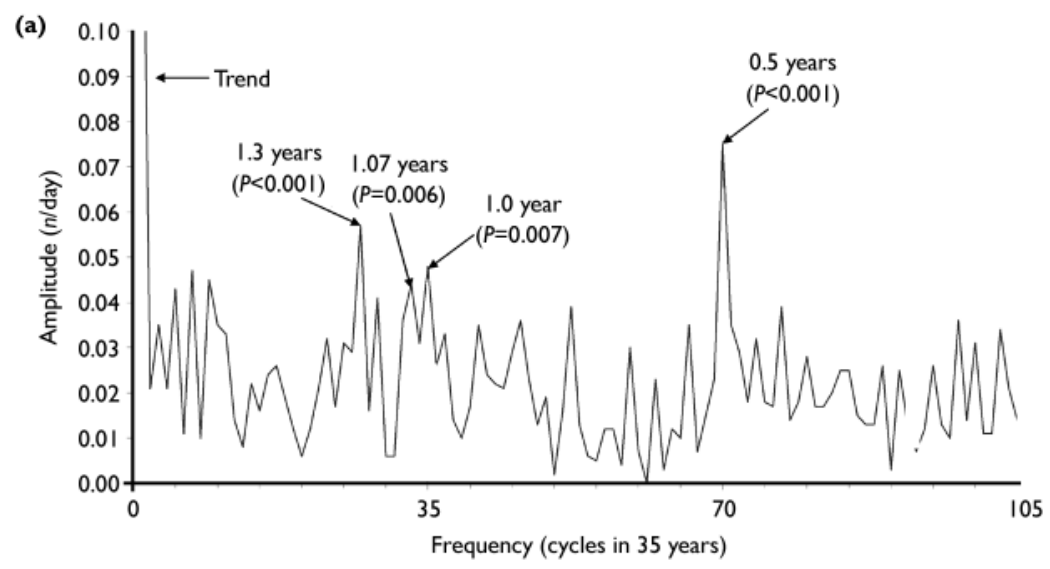

(b)

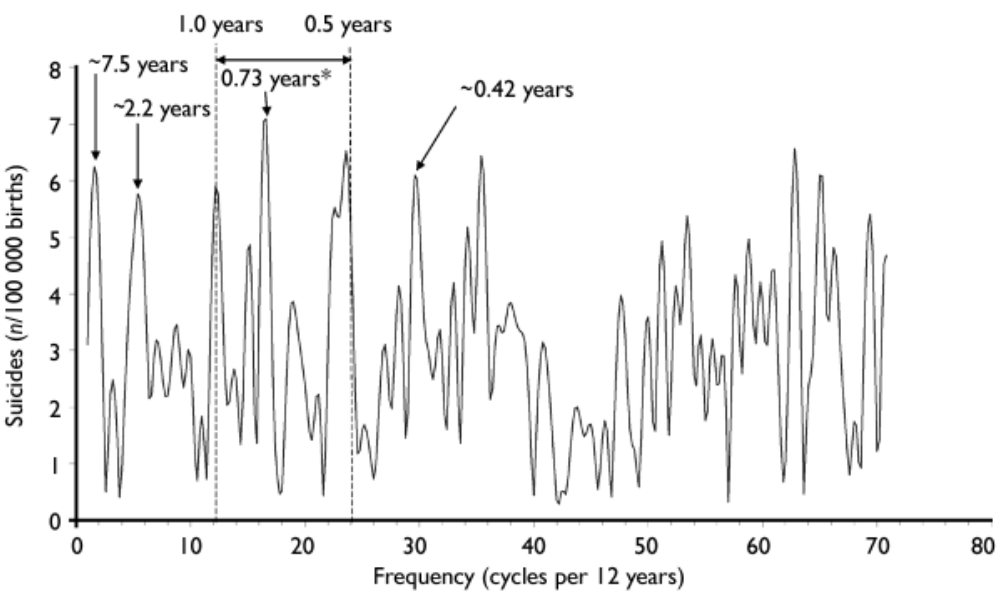

Fig. I (a) Suicides in Minnesota according to calendar date of death (1968-2002); (b) suicides in England and Wales according to calendar month of birth. *Validated non-linearly: period $=0.727$ years $(95 \% \mathrm{Cl} 0.703-0.75 \mathrm{I})$. Data from Salib \& Cortina-Borja (2006). 